\title{
Failure Mode and Capacity of Suction Caisson under Inclined Short-term Static and One-way Cyclic Loadings
}

\author{
Zhen Guo ${ }^{1}$, Dong-Sheng Jeng ${ }^{2}$, Wei Guo ${ }^{3}$, Lizhong Wang ${ }^{\text {* }}$ \\ ${ }^{1}$ Key Laboratory of Offshore Geotechnics and Material of Zhejiang Province, Research Center \\ of Coastal and Urban Geotechnical Engineering, College of Civil Engineering and Architecture, \\ Zhejiang University, Hangzhou, 310058, China. \\ ${ }^{2}$ Griffith School of Engineering, Griffith University Gold Coast Campus, Queensland, QLD \\ 4222, Australia. \\ ${ }^{3}$ National Engineering Laboratory for High Speed Railway Construction, School of Civil \\ Engineering, Central South University, Changsha, 410075, China. \\ * Corresponding author: Prof. Lizhong Wang.
}

The author affiliations are as follows:

Dr. Zhen Guo

Associate Professor

Key Laboratory of Offshore Geotechnics and Material of Zhejiang Province

College of Civil Engineering and Architecture, Zhejiang University, Hangzhou 310058, China.

E-mail: nehzoug@163.com

\section{Dr. Dong-Sheng Jeng}

Professor

Griffith School of Engineering, Griffith University Gold Coast Campus

Queensland, QLD 4222, Australia.

E-mail: d.jeng@griffith.edu.au

\section{Dr. Wei Guo}

Associate Professor

National Engineering Laboratory for High Speed Railway Construction

School of Civil Engineering, Central South University

Changsha 410075, Hunan, China.

E-mail:wei.guo.86@gmail.com.

\section{Dr. Lizhong Wang (Corresponding author)}

Professor

Key Laboratory of Offshore Geotechnics and Material of Zhejiang Province

College of Civil Engineering and Architecture, Zhejiang University, Hangzhou 310058, China.

E-mail:wlzzju@163.com 


\begin{abstract}
In addition to the loading angle at the pad-eye, the types of applied forces will affect the failure mode and the capacity of suction caisson in a soft clay seabed. In this study, a specially designed platform was used to carry out model tests with different loading angles and cyclic parameters. First, the short-term static capacities and the failure modes for the typical inclined loading angles were studied, and then the influences of the cyclic amplitude, the number of cycles and the cyclic period on the subsequent failure mode and the caisson capacity were investigated by applying a series of one-way cyclic loadings. The experimental results showed that when the loading angle decreases from $50.2^{\circ}$ to $32.0^{\circ}$, the model caisson's failure mode changes to a combined mode consisting vertical motion, horizontal motion and anticlockwise rotation, and its corresponding capacity noticeably increases. However, the increases in the amplitude, the number and the frequency of the previous cyclic loadings would turn this combined failure into a dominant vertical pullout and reduce its capacity to some degree. Therefore, the influence of the previous cyclic loadings should be taken into account to accurately estimate the holding capacity of the suction caisson.
\end{abstract}

Keywords: suction caisson; soft clay; failure mode; inclined capacity; short-term static loading; one-way cyclic loading 


\section{Introduction and Background}

In the past few decades, suction caisson has been increasingly used as an effective solution for anchoring in deep water $[1,2]$. Suction caisson is a large, steel-made and thin-walled structure, which is open at the bottom and closed at the top. Compared with traditional pile and drag-embedded anchor, the suction caisson has several significant advantages including its easy handling of the field installation, accurate positioning, greater pullout capacity and adaptability for complicated loading conditions.

During the field installation, the suction caisson is penetrated into the seabed by the dead weight (its self weight and the ballast) and the downward pressures (the suction caused by water pumping) in sequence. Then, the caisson capacity increases with the dissipation of the excess pore-pressure and the soil strength build-up due to the thixotropy. This procedure is typically called the "set-up" process which may take several days or even months. After this set-up stage, the slack in the mooring line should be removed by using a winch to slowly pretension the attached mooring line, which connects the fairlead with the pad-eye. Thus, the suction caisson can provide effective constraints to the floating facility through the attached mooring line. For a typical taut or semi-taut mooring system (TMS), the elevation angle of the mooring line at the pad-eye lies between $30^{\circ}$ and $50^{\circ}$ from the horizontal.

While in service, the pullout capacity of suction caisson is mainly determined by its geometrical dimensions, the embedded depths, the surrounding soil properties, the loading positions, the elevation angles and the types of acting forces that are passed from the attached mooring line. For a suction caisson in a specific location, the routine design strategy is to obtain its "optimal" loading position. Ideally, if the passed force acts on this optimal position all of the time, the failure mode of the suction caisson will be mainly composed of translational displacements with minimal rotations, and thus the inclined capacity of the suction caisson can reach the peak value. EI-Sherbiny [3] suggested that the optimum position should be about $2 / 3$ to $3 / 4$ of the embedded depth for a suction caisson in normally consolidated clay. Andersen et al. [4] indicated that for normally consolidated or over-consolidated clay, the optimal loading position is for $D^{* / L} \sim 0.65$ to 0.7 , as shown in Fig. 1, where $D^{*}$ is the depth at which the loading direction and the centre axis intersect, and $L$ is the caisson embedded depth.

As indicated by Randolph \& House [5], the essence for selecting an optimal loading position is to make the centre of the caisson rotation lying at infinity when the suction caisson is pulled. However, the loads that are passed by the mooring line are much more complicated in deepwater environment. Therefore, it is 
inappropriate to assess the optimal position based only on the above discussions.

Due to the greater environmental loads that are encountered in service, the pre-tensioned mooring line tends to cut into the seabed further [6], and the elevation angle of the load at the pad-eye will gradually decrease to some degree. Accordingly, the intersection of the loading direction and the centre axis will move upward, and thus the suction caisson will be inclined to produce a clockwise rotation at failure. The capacity of the suction caisson depends on whether an open crack can develop along the active side of the caisson wall during loading, because water communication through this crack to the caisson tip level can be critical. Based on this consideration, both Andersen \& Jostad [7] and API RP 2SK [8] suggested that the pad-eye should be positioned just below the optimal depth in order to ensure a backward rotation.

The force passed by the mooring line in the field is not only a static tension force; instead, it can be divided into three main types of forces (Fig. 2):

- There are the steady loads that are mainly contributed by line pretension, wind, current and wave drift forces, which are constant in magnitude and direction for the duration of interest.

- There are the low-frequency cyclic loads, which have periods ranging from 60 to $600 \mathrm{~s}$.

- There are the high-frequency cyclic loads, which have typical periods ranging from 5 to $30 \mathrm{~s}$ (near the wave frequency).

Among these three types of forces, the steady loads may be the largest, while the low-frequency cyclic loads tend to excite the deepwater platform at its natural periods in surge, sway and yaw. The different types of forces acting on the suction caisson can change the surrounding soil properties to some degree as well as the loading condition.

To simplify the analysis, most previous researches $[1,2]$ only focused on the failure mode and the capacity of suction caisson under vertical or inclined short-term static tensioning, in which cases the soil around the caisson suffers an undrained loading condition. Additionally, the current dynamic analysis for suction caisson is entirely based on this type of short-term static capacity and the corresponding failure mode. In the design, the effects of dynamic loadings are only taken into account through the adoption of a factor of safety $(F O S)$ according to the failure modes under the short-term static tensioning. According to API RP 2SK [8], the vertical pullout failure mode has the highest $F O S$, while the horizontal motion failure mode has the lowest FOS and the combined failure mode has an "average" FOS in a sense. However, sustained and cyclic loadings disturb the soil and change the drainage condition of the 
surrounding soil under an inclined loading. These influences greatly affect the suction caisson's failure mode, which will be quite different from that under static loadings. Some researchers [9-13] investigated the influences of sustained and cyclic loadings on the caisson pullout capacity and found that these loadings noticeably reduce the capacity of the suction caisson. However, there are few discussions about the failure mode for a suction caisson under these loading cases until now. This paper is aimed at investigating the influences of the load elevation angles and the different cyclic loading parameters, such as the cyclic amplitude, the number and the period, on the failure mode and the capacity of a suction caisson in a soft clay seabed.

\section{Model Test Equipments}

\subsection{Model Caisson}

A steel model caisson with a length of $400 \mathrm{~mm}$ has been used in this study. The model caisson's diameter and wall thickness are $88 \mathrm{~mm}$ and $2 \mathrm{~mm}$, respectively. The sealed top cap extends $20 \mathrm{~mm}$ inside the tube, and thus the expected embedment-to-diameter ratios can reach 4.3. The total mass of the model caisson is $3.20 \mathrm{~kg}$. The top cap has one threaded attachment that is used to connect the insertion/pullout rod to the caisson and several ports for the pore-pressure instrumentation, the venting and the vacuum application. In addition, a vertical pad-eye plate is welded to the outside of the model caisson to allow the adjustment of the loading point.

During the model tests, the excess pore water pressures along the caisson wall can be measured by pore-pressure transducers (PPTs) at different locations, which are denoted by $I_{1}, I_{2}, O_{1}, O_{2}, O_{3}$ and $O_{4}$ in Fig. 3. Additionally, a pressure sensing line connected to point $U$ is to measure the pressure below the top cap.

\subsection{Preparation of Test Bed Soil.}

A painted steel tank, which is $3.0 \mathrm{~m}$ long, $1.2 \mathrm{~m}$ wide and $1.5 \mathrm{~m}$ high, was used to prepare the test bed soil by mixing several batches of slurry and carefully pouring into the tank. The initial water content of the as-prepared slurry was approximately $90 \%$ to $100 \%$. To accelerate the slurry consolidation, a drainage layer was deployed at the bottom of the tank, and a layer of bricks with an underlying geotextile were placed on the clay surface. After about six months of consolidation, the upper bricks and the geotextile were removed that resulted in an over-consolidation condition of test bed soil. The water content and the 
total unit weight are obtained from soil samples that were acquired with a piston sampler (Fig. 4(a) and

(b)). In addition, the over-consolidation ratio (OCR) of the test bed soil is plotted in Fig. 4(c). The liquid limit of the clay ranges from $43 \%$ to $49 \%$, and the plasticity index ranges from $24 \%$ to $28 \%$. The consolidation coefficient $c_{\mathrm{v}}$ lies between $0.03 \sim 0.05 \mathrm{~mm}^{2} / \mathrm{s}$. The undrained shear strength and the soil sensitivity were measured in situ using two vane shear tests, as shown in Figs. 5(a) and (b).

\subsection{Equipments and Test Procedure}

Generally speaking, the model caisson should be penetrated into the test bed soil by the dead weight and the suction in sequence to simulate the field installation process. However, as suggested in previous work by Guo et al. [14], different magnitudes and types of suction application will greatly affect the disturbance degree of the surrounding soil and produce different final soil heaves inside of the caisson. It will be difficult to either precisely control or quantitatively estimate the influence of the suction penetration process. Thus, focusing only on the effects of the different loading conditions, the model caisson in this study is uniformly jacked into the soil using the dead-weight loading rig [14], as shown in Fig. 6(a) and (b). The final penetration depth is $380 \mathrm{~mm}$, and during this jacking process, the load cell and the linear variable differential transformer (LVDT) measure the vertical resistance and the displacement of model caisson.

It should be noted that a thin steel wire is pre-attached to the pad-eye plate before the caisson penetration, and the attachment point is located approximately $258 \mathrm{~mm}$ (about $0.68 \mathrm{~L}$, where $L$ is the embedded depth) from the top cap; this location is just below the optimal loading position according to the discussions in section 1 . Once the model caisson reaches a sufficient penetration depth, the steel wire can be tensioned slowly until the slack in the wire is completely removed. Then, after the excess pore-pressures in surrounding soil fully dissipate, the inclined static or cyclic loading tests of the model caisson can be performed using the inclined loading equipment, which mainly contains inclined static and one-way cyclic loading parts, as shown in Fig. 7.

During inclined static loading tests, the inclined load at the pad-eye is applied through a constant tensioning the attached wire by the stepper motor with a drawing bar; in contrast, the test procedure becomes more complicated for the one-way cyclic loading tests in this paper, as shown in Fig. 8. First, the attached wire is pre-tensioned at a constant rate to achieve an initial tension level; then, a certain number of one-way cyclic loadings can be applied by rotating an eccentric wheel at a certain eccentric distance 
and a certain rotation period; afterwards, the inclined static loading is immediately applied on the model caisson to obtain its resistance peak and the corresponding failure mode.

During the entire model test process, the inclined resistance, the displacement and the changes in the pore-pressures around the caisson can be recorded by the load cell, the LVDT and the PPTs, respectively. Particularly, the motion trajectory of the model caisson under an inclined loading can be measured by the motion-measurement system, which was first put forward in the work of EI-Sherbiny [3]. As shown in Fig. 9, a two-dimensional coordinate system $X O Z$ is set up first. Based on some of the known parameters and the variables measured by the LVDTs and the tilt meter, the motion of the model caisson can be obtained through a simple geometrical analysis and calculation. Here, using the typical point $P$ (the attachment point at the pad-eye plate) as an example, when point $P$ moves from its original position $\left(x_{p}, z_{p}\right)$ to a new position $\left(x_{p^{\prime}}, z_{p^{\prime}}\right)$, its new coordinates can be updated as

$$
\begin{gathered}
x_{P^{\prime}}=x_{B}+c \cdot \cos \left(\theta_{A}\right)+S \cdot \sin (\beta+\varphi) \\
z_{P^{\prime}}=z_{B}+c \cdot \sin \left(\theta_{A}\right)+S \cdot \cos (\beta+\varphi)
\end{gathered}
$$

where $x_{B}$ and $z_{B}$ are the original coordinates of point $B$ before the caisson moves; $c$ and $\theta_{A}$ are the side length and the interior angle of triangle $A B C ; S=\sqrt{\left(L_{1}+C L+R L\right)^{2}+d^{2}}$, where the denotations of $L_{1}, C L, R L$ and $d$ are illustrated in Fig. 9; $\beta$ is the intersection angle of the two lines, as shown in Fig. 9; $\varphi$ is the inclination angle of the model caisson from the vertical direction. In the above

parameters, $x_{B}, z_{B}, S$ and $\beta$ are constant during the model caisson's motion, while $c, \theta_{A}$ and $\varphi$ should be updated at each step with the model caisson's motion, which can be measured by the LVDTs and the tilt meter.

\section{Model Test Arrangement}

In this paper, twelve model tests were performed in over-consolidated soft clay, as shown in Table 1. The tests can be divided into two sets: in the set containing LP-1, LP-2 and LP-3, the load elevation angle typically changes from $50.2^{\circ}$ to $30.0^{\circ}$, and an inclined loading rate of $1 \mathrm{~mm} / \mathrm{s}$ is adopted; in the set containing tests NP-1 to NP-9, the effects of previous cyclic loadings are studied. In this set, the cyclic amplitude decreases gradually ("large", "medium" and "small"), the cyclic period ranges from 10 to $100 \mathrm{~s}$, 
and the number of cycles ranges from 50 to 200. After a series of cyclic loadings, an inclined loading test with a constant tensioning rate of $1.0 \mathrm{~mm} / \mathrm{s}$ is carried out.

Deng \& Carter[15] have recommended that a normalized velocity be used to assess the failure mode of a suction caisson that is only under a vertical pullout:

$$
T_{k}=\frac{c_{v}}{v D}
$$

where $v$ is the vertical upward displacement rate $(\mathrm{mm} / \mathrm{s}) ; D$ is the diameter of the suction caisson $(\mathrm{mm})$; $c_{v}$ is the consolidation coefficient for the soil $\left(\mathrm{mm}^{2} / \mathrm{s}\right)$. For soft clay, the authors suggest that when $T_{k}<0.002$ is fulfilled, the caisson behaves as it would under a reverse end-bearing condition, and the pullout capacity of the suction caisson reaches the peak value. This loading state is generally called the "undrained" condition of the surrounding soil. Similarly, this normalized velocity is thought to be also appropriate to assess the drainage condition around the caisson for an inclined static pullout. According to section 2.2, the consolidation coefficient $c_{v}$ of the test bed soil lies between $0.03 \sim 0.05 \mathrm{~mm}^{2} / \mathrm{s}$. Therefore, for the model caisson with a diameter of $88 \mathrm{~mm}$, an inclined loading rate of $1 \mathrm{~mm} / \mathrm{s}$ is sufficient to maintain the undrained condition of the surrounding soil.

\section{Test Results and Interpretation}

\subsection{Inclined Static Pullout Tests at Different Loading Angles}

As described in the previous section, the attachment point is located approximately $0.68 \mathrm{~L}$ from the top cap. Different loading elevation angles $\left(50.2^{\circ}, 42.8^{\circ}\right.$ and $\left.32.0^{\circ}\right)$ at the pad-eye are adopted in tests LP-1, LP-2 and LP-3, respectively. In all these tests, the motion of the model caisson can be characterized by the translation of the pad-eye and the rotation of the caisson's central axis, as illustrated in Fig. 10. When the loading angle at the pad-eye decreases from $50.2^{\circ}$ in test LP- 1 to $32.0^{\circ}$ in test LP-3, the model caisson's failure mode clearly changes from the dominant vertical upward motion to a combination of vertical, horizontal displacements and anticlockwise rotation. The anticlockwise rotation becomes quite obvious for test LP-3 with loading angle $32.0^{\circ}$, whose final tilt degree of the model caisson reaches $13.5^{\circ}$. It can also be noted that due to an unavoidable, small initial tilt error (only $0.03^{\circ}, 0.11^{\circ}$ and $0.03^{\circ}$ from the vertical direction) during the caisson installation, the actual initial position of the pad-eye always deviates 
slightly from its design position, as shown in Fig. 10. However, all of the initial errors in these three tests do not exceed $2.0 \mathrm{~mm}$, and can thus be ignored in the analysis.

Fig. 11 shows the data from several PPTs along the caisson wall in tests LP-1, LP-2 and LP-3. For test LP-1, as shown in Fig. 11(a), the changes of the pore-pressures at $I_{1}$ and $O_{2}$ are the most obvious, due to the combination of the vertical, horizontal motions and the anticlockwise rotation of the model caisson; the negative pore-pressure at $I_{2}$, which is slightly lower than those at $I_{1}$ and $O_{2}$, is only induced by the obvious upward motion of the model caisson; the negative pressure at $U$, which is typically called the "passive suction", balances the weight of the interior soil plug and the reverse end bearing resistance near the caisson tip, and ensures that the interior soil plug moves together with the upward-moving model caisson; the pore-pressure at $O_{1}$ does not change significantly, because although the upward motion of the model caisson tends to decrease the pore-pressure at $O_{1}$, this decrease is suppressed by the horizontal motion and the anticlockwise rotation of the model caisson.

Fig. 11(b) shows the changes of pore-pressures along the caisson wall in test LP-2. It can be noted that the pore-pressure changes are similar to those in test LP-1, except for the fact that the pore-pressure at $O_{1}$ has a slightly higher positive pressure due to the larger horizontal motion in test LP-2 than that is test LP-1. Fig. 11(c) illustrates the pore-pressure changes along the caisson wall in test LP-3. The pore-pressures in tests LP-3 differ from those in tests LP-1 and LP-2 in that there are much lower negative pore-pressures at $I_{1}$ and $O_{2}$, which is thought to be due to larger displacement in this test.

As shown in Fig. 12(a), the development of the inclined resistance to the model caisson is essentially related to the variation of the failure mode. For test LP-1, which mainly exhibits a vertical upward pullout failure mode, the increase velocity of the resistance versus the caisson displacement is greatest at the beginning. The increase velocity decreases slightly as the horizontal motion and the anticlockwise rotation become more pronounced. Finally, the resistance reaches a peak of $379 \mathrm{~N}$ at a displacement of approximately $25.9 \% D$, where $D$ is the diameter of model caisson. For test LP-2, the loading angle at the pad-eye is decreased to $42.8^{\circ}$, and the main failure mode of model caisson is vertical pullout. However, there is some degree of horizontal motion during the beginning of the inclined loading. This horizontal motion lessens the increase velocity of the soil resistance. At a displacement of $25.0 \% D$, the resistance reaches a peak of $420 \mathrm{~N}$, which is similar with the results in test LP-1. Test LP-3 has the smallest loading angle of the three inclined loading tests. In this test, the failure mode is a combination of vertical motion, 
horizontal motion and anticlockwise rotation, and the increase velocity of the soil resistance is less than those in tests LP-1 and LP-2. The resistance peak $(544 \mathrm{~N})$ at a displacement of $47.6 \% D$, which is larger than displacements at which the peaks in the previous tests occurred, is much greater than the resistance peaks in tests LP-1 and LP-2. From an engineering perspective, the critical design focus is the ultimate capacity of the suction caisson rather than its displacement in the seabed, so adopting a lower loading angle at the pad-eye can be beneficial for the safety of the anchor capacity. Fig. 12(b) plots the components of the load that is acting on the pad-eye during inclined static pullout tests. It can be seen that the greater resistance with a lower loading angle in the test is mainly due to the horizontal component, as the vertical component of the caisson capacity is similar in all three tests. According to the test soil data in Fig. 4 and Fig. 5, the vertical uplift capacity of suction caisson can be calculated based on the work of Thorel et al. [16]. The equation for the pullout capacity of suction caisson is shown as follows,

$$
F_{u}=W_{p}+W_{s}+\alpha_{e} \cdot \overline{S_{u}} \cdot A_{1}+N \cdot S_{u}(L) \cdot A
$$

where $F_{\mathrm{u}}$ is the vertical uplift capacity of suction caisson; $W_{\mathrm{p}}$ and $W_{\mathrm{s}}$ are the submerged weights of the

caisson and soil plug; $\alpha_{e}$ is external skin friction factor; $\bar{S}_{u}$ is the average undrained shear strength of soil from the mudline $\mathrm{z}=0$ to tip depth $\mathrm{z}=L ; A_{1}$ is the external surface area of caisson wall; $N$ is the reverse bearing capacity factor varying from 6.2 to 9.0 depending on caisson penetration depth/diameter ratio; $S_{u}(L)$ is the undrained shear strength of soil at the tip depth $\mathrm{z}=L ; A$ is the plan area of the caisson. Thus, the calculated pullout capacity of model caisson is equal to $283.84 \mathrm{~N}$, which coincides well with the peak of vertical component of the caisson capacity.

\subsection{Inclined Cyclic Loading Tests}

To investigate the effect of earlier cyclic loadings on the failure mode and the pullout capacity of the suction caisson, nine inclined cyclic loading tests were performed in this study, as shown in Table 1. The loading point is also located about $0.68 \mathrm{~L}$ from the top cap, and the original loading angle is approximately $32.0^{\circ}$. For comparison, the inclined capacity of the model caisson in test LP-3 is taken as the reference capacity, which can be called the short-term static capacity (SC). Among these tests, three different cyclic amplitudes ranging from "large" to "small" are adopted in tests NP-1, NP-2 and NP-3. The cyclic numbers studied range from 50 to 200, and the cyclic periods from 10 to $100 \mathrm{~s}$, see Table 1 .

(1) Effect of the cyclic amplitude

Before the cyclic loadings, the attached steel wire is pre-tensioned to achieve initial tension levels, 
which are 208N (38.2\% SC) for NP-1, 200 N (36.8\% SC) for NP-2 and 204 N (36.8\% SC) for NP-3, respectively. By adjusting the eccentric distance of the wheel (section 2.3), three cyclic amplitudes ranging from "large" to "small" are applied in tests NP-1, NP-2 and NP-3. Fig. 13 gives the cyclic loading processes of tests NP-1, NP-2 and NP-3. Due to the gradual relaxation of the tensioned wire, the initial tension level always decreases to a lower magnitude after the first several cycles and then becomes steady. The final tension levels for tests NP-1, NP-2 and NP-3 are $110 \mathrm{~N}(20.2 \%$ SC), $128 \mathrm{~N}(23.5 \% \mathrm{SC})$ and 153 $\mathrm{N}(28.1 \% \mathrm{SC})$; their corresponding cyclic amplitudes are $50 \mathrm{~N}(9.2 \% \mathrm{SC}), 42 \mathrm{~N}(7.7 \% \mathrm{SC})$ and $35 \mathrm{~N}$ $(6.4 \% \mathrm{SC})$, respectively.

After 50 cyclic loadings, the model caisson produces some displacements, which can be denoted by the motion of the pad-eye and the caisson tilt degree. As shown in Fig. 14, the hollow markers are the initial position of the pad-eye, and the solid markers are the new position after the cyclic loadings. The short straight lines represent the tilt degree of the model caisson's centre axis. In test NP-1, the motion of the pad-eye is mainly a vertical displacement of approximately $7.3 \mathrm{~mm}$, and the tilt degree simultaneously changes from $0.12^{\circ}$ to $0.68^{\circ}$. In test NP-2, the model caisson is more inclined to move horizontally, with a total displacement of $5.9 \mathrm{~mm}$ and a caisson tilt degree varying from $0.06^{\circ}$ to $0.81^{\circ}$. The displacement of the pad-eye in test NP-3, $1.9 \mathrm{~mm}$, is the smallest of the tests and is composed of $0.9 \mathrm{~mm}$ horizontal and $1.9 \mathrm{~mm}$ vertical displacements. In test NP-3, the tilt degree of the model caisson is almost unchanged, with a variation from $0.17^{\circ}$ to $0.23^{\circ}$. As shown in Fig. 14 , the errors between the actual initial position of the pad-eye and its design position in these tests do not exceed $3.0 \mathrm{~mm}$, and can thus be ignored.

Once the cyclic loadings are completed, the inclined static pullout of the model caisson is performed immediately. Hence, the motion process of the model caisson can be obtained, as shown in Fig. 15(a). The solid markers correspond to the peaks of the inclined resistance. Fig. 15(b) illustrates the curves of the resistance versus the pad-eye displacement in tests NP-1, NP-2 and NP-3, as well as the result of test LP-3 with the same loading angle $\left(32.0^{\circ}\right)$ for comparison.

As shown in Figs. 15(a) and (b), the model caisson in test NP-1 first produces some small horizontal displacements after the cyclic loadings with large cyclic amplitude, and then shows an obvious vertical pullout failure mode. The anticlockwise rotation of the model caisson in test NP-1 is not obvious, with a maximum of $1.50^{\circ}$. At a displacement of $15.9 \mathrm{~mm}(9.8 \% \mathrm{D})$, the resistance reaches the peak of $271 \mathrm{~N}$, which is only approximately half of the resistance peak $(544 \mathrm{~N})$ in test LP-3. Another obvious 
phenomenon is that the increase velocity of the soil resistance in the initial loading stage of test NP-1 is greater than that in test LP-3.

In test NP-2, after the medium cyclic amplitude loadings, the translational motion (vertical and horizontal) of the model caisson is similar to that of test NP-1, but the anticlockwise rotation degree at failure is equal to $4.78^{\circ}$, which is larger than that of test NP-1. The inclined soil resistance reaches a peak of $400 \mathrm{~N}$ at the displacement of $32.7 \mathrm{~mm}(37.2 \% D)$. This resistance is lower than that in test LP-3 but higher than that in test NP-1. The increase velocity of the resistance is greater than those in tests LP-3 and NP-1.

Test NP-3 has the lowest cyclic amplitude of the above model tests. The inclined resistance peak is equal to $576 \mathrm{~N}$, and the corresponding displacement and the degree of anticlockwise rotation are $52.9 \mathrm{~mm}$ $(60.1 \% D)$ and $6.60^{\circ}$, respectively. The results in this test are very similar to those of test LP-3, except for the increase velocity of the soil resistance. The resistance in the initial loading stage of test NP-3 increases more quickly than that of test LP-3, due to the change in the motion mode from a combined mode to vertical pullout. As evidence, when the failure modes of the model caisson in tests NP-3 and LP-3 are similar (a combination of vertical motion, horizontal motion and anticlockwise rotation) in the latter loading stage, the increase velocities of their resistances are also similar.

Therefore, when previous cyclic amplitude is large, the failure mode of the model caisson under inclined static loading tends to be dominated by vertical pullout. This is due to the continuous, large cyclic loading that causes a greater disturbance to the surrounding soil and a greater loss in the interface strength between the caisson wall and the soil. When the cyclic amplitude is small, the previous cyclic loading has little influence on the final failure and the inclined capacity of the model caisson; instead, the previous cyclic loading only affects the motion mode of the model caisson and the increase velocity of the resistance in the initial loading stage.

(2) Effect of the number of cycles

As shown in Fig. 16, the same tension level of about 220 N (36.8\% SC) is adopted in tests NP-3, NP-4 and NP-5, with 50, 100 and 200 cycles, respectively. After several cyclic loadings, the tension level gradually levels out at approximately $150 \mathrm{~N}(27.6 \% \mathrm{SC})$, and the cyclic amplitude is equal to $35 \mathrm{~N}(6.4 \%$ SC).

For tests NP-3, NP-4 and NP-5, the original deviations of the pad-eye position from the design position 
are not larger than $3.0 \mathrm{~mm}$. Fig. 17 shows the displacements of the model caisson after 50, 100 and 200 cyclic loadings. In tests NP-3, NP-4 and NP-5, the displacements of the pad-eye are $1.9 \mathrm{~mm}, 3.0 \mathrm{~mm}$ and $2.3 \mathrm{~mm}$, respectively, and the tilt degrees of the model caisson increase to $0.23^{\circ}, 0.81^{\circ}$, and $0.23^{\circ}$, respectively.

Then, the model caisson is tensioned at a constant velocity of $1 \mathrm{~mm} / \mathrm{s}$. The motions of the model caisson in tests NP-3, NP-4 and NP-5 are shown Fig. 18(a), in which the solid markers correspond to the peaks of the inclined resistance. Fig. 18(b) shows the curves of the inclined resistance versus the pad-eye displacement in tests NP-3, NP-4 and NP-5, as well as the results of test LP-3 with no previous cyclic loadings as a reference.

When the cycle number increases from 0 to 200 , the failure mode and the inclined capacity of the model caisson change significantly. As described above, there is no obvious difference in the resistance peaks and the failure modes of tests NP-3 (50 cycles) and LP-3 ( 0 cycle). The resistance peaks are $576 \mathrm{~N}$ and $544 \mathrm{~N}$ for tests NP-3 and LP-3, respectively, while the corresponding displacements are $52.9 \mathrm{~mm}$ $(60.1 \% \mathrm{D})$ and $41.9 \mathrm{~mm}(47.6 \% \mathrm{D})$, and the corresponding degrees of anticlockwise rotation of the model caisson are $6.60^{\circ}$ and $7.24^{\circ}$. While the number of cycles gradually increases to 100 and 200 in tests NP-4 and NP-5, the failure mode gradually changes to vertical pullout, and the inclined capacity noticeably decreases. The resistance peaks of tests NP-4 and NP-5 are $433 \mathrm{~N}$ and $441 \mathrm{~N}$, respectively, while the corresponding displacements are $7.4 \mathrm{~mm}(8.4 \% D)$ and $5.7 \mathrm{~mm}(6.5 \% D)$, and the corresponding degrees of anticlockwise rotation of the model caisson are $1.32^{\circ}$ and $0.67^{\circ}$. In tests NP-3, NP-4 and NP-5, the increase velocities of the resistance are similar after previous cyclic loadings, especially in the initial loading stage.

(3) Effect of the cyclic period

Figs. 19(a), (b), (c) and (d) show the cyclic loading processes for the different periods in tests NP-6, NP-7, NP-8 and NP-9. For tests NP-6 and NP-7, the cyclic periods are both $50 \mathrm{~s}$, and there are 50 and 100 cycles, respectively. For tests NP-8 and NP-9, the cyclic periods are both $100 \mathrm{~s}$, and there are 50 and 100 cycles, respectively. In these four model tests, the same original tension level of $220 \mathrm{~N}(36.8 \% \mathrm{SC})$ is adopted. The final steady tension level ranges from $110 \mathrm{~N}(20.2 \% \mathrm{SC})$ to $144 \mathrm{~N}(26.5 \% \mathrm{SC})$, and the cyclic amplitude lies between $30 \mathrm{~N}(5.5 \% \mathrm{SC})$ and $38 \mathrm{~N}(7.0 \% \mathrm{SC})$ 。

After a series of cyclic loadings of different periods and numbers in tests NP-6, NP-7, NP-8 and NP-9, 
the displacements of the pad-eye are $3.4 \mathrm{~mm}, 3.2 \mathrm{~mm}, 2.7 \mathrm{~mm}$ and $2.1 \mathrm{~mm}$, respectively. The changes in the caisson tilt after these cyclic loadings are illustrated in Fig. 20. Due to the installation errors in the model tests, the distances between the actual position of the pad-eye and its design position are $3.0 \mathrm{~mm}$, $2.0 \mathrm{~mm}, 2.2 \mathrm{~mm}$ and $1.6 \mathrm{~mm}$ for tests NP-6, NP-7, NP-8 and NP-9, respectively.

To study the effect of the cyclic period on the failure mode and the inclined capacity of the model caisson, the results of tests NP-6, NP-7, NP-7 and NP-8 are divided into two sets: one contains tests NP-6 and NP-8, in which there are 50 cycles, and the cyclic periods are $50 \mathrm{~s}$ and $10 \mathrm{~s}$, respectively; the other set includes tests NP-7 and NP-9, in which 100 cyclic loadings are applied, and the cyclic periods are $50 \mathrm{~s}$ and $10 \mathrm{~s}$, respectively.

Figs. 21(a) and (b) show the motions and the inclined resistances of the model caisson in tests NP-6 and NP-8, as well as the results of tests LP-3 and NP-3 for comparison. In Fig. 21(a), the solid markers are related to the peaks of the inclined resistance. After only 50 low-frequency $(0.01 \mathrm{HZ}$, period of $100 \mathrm{~s})$ cyclic loadings in test NP-3, the failure mode and the inclined capacity of the model caisson coincide well with those of test LP-3, in which there was no pervious cyclic loading. For the higher frequency cyclic loadings in tests NP-6 $(0.02 \mathrm{HZ}$, period of $50 \mathrm{~s})$ and NP-8 $(0.1 \mathrm{HZ}$, period of $10 \mathrm{~s})$, the peaks of the inclined resistance noticeably decrease to $415 \mathrm{~N}$ and $462 \mathrm{~N}$, respectively. The displacements decrease to $17.4 \mathrm{~mm}(19.8 \% D)$ and $19.6 \mathrm{~mm}(22.3 \% D)$ in tests NP-6 and NP-8, and the corresponding degrees of anticlockwise rotation of the model caisson reach $2.31^{\circ}$ and $2.90^{\circ}$. As shown in Fig. 21(b), at the initial loading stage in tests NP-3, NP-6 and NP-8, the motion modes of the model caisson show no significant differences, and the increase velocities of the inclined resistance are also similar.

The cyclic periods in tests NP-7 and NP-9 are also 50s and 10s, respectively, but their cycle numbers increase to 100. As shown in Figs. 22(a) and (b), the resistance peaks for tests NP-7 and NP-9 are similar with the resistances of tests NP-6 and NP-8 with 50 cycles, but their corresponding displacements are only $4.7 \mathrm{~mm}(5.3 \% \mathrm{D})$ and $6.4 \mathrm{~mm}(7.3 \% \mathrm{D})$ with greater increase velocities of the inclined resistance. The tilt degrees of the model caissons in tests NP-7 and NP-9 reach $0.81^{\circ}$ and $0.68^{\circ}$, respectively. It can be concluded that although the cyclic periods of tests NP-4, NP-7 and NP-9 are quite different (100 s, $50 \mathrm{~s}$ and $10 \mathrm{~s}$ ), their failure modes and inclined capacities become similar as long as the number of previous cyclic loadings reaches 100 . 


\section{Conclusions}

In this paper, the effects of loading angles are first studied through changing the elevation angle of attached line. Then, after applying a number of one-way cyclic loadings, the model caisson was pulled out at a certain loading angle to obtain the failure modes and corresponding capacities. The effects of the parameters of previous cyclic loadings, such as the amplitude, number and period of the cycles, are investigated in detail. Based on the model tests, some useful conclusions and suggestions can be drawn as follows:

(1) When the loading angle at the pad-eye decreases from $50.2^{\circ}$ to $32.0^{\circ}$, the failure mode of the model caisson tends to change from a vertical pullout to a combined failure mode, which is composed of vertical motion, horizontal motion and anticlockwise rotation. Accordingly, the peak of the inclined resistance to the model caisson increases, but the increase velocity of inclined resistance noticeably decreases.

(2) With an increase in the cyclic amplitude, the model caisson tends to produce obvious displacements under a series of previous cyclic loadings, which evidently disturb the surrounding soil to a greater degree and further reduce the interface strength between the caisson wall and the soil. These effects cause the model caisson under the inclined static loading to move vertically at failure rather than produce combined motions, and the corresponding inclined capacity of the model caisson obviously decreases.

(3) When there are only 50 cycles, previous cyclic loadings only slightly influence the failure mode and the inclined capacity of model caisson, which are similar to those in the test with no previous cyclic loading test; however, when the number of cycles increases to 100 or 200 , the failure mode and the capacity tend to be similar for different numbers of cycles, with a dominant vertical pullout failure and a noticeably reduced capacity.

(4) For cyclic periods of $100 \mathrm{~s}, 50 \mathrm{~s}$ and $10 \mathrm{~s}$, when there are only 50 cycles, the cyclic loadings with shorter periods (50 s or $10 \mathrm{~s}$ ) cause the model caisson to produce more vertical motion under subsequent inclined static loading than the $100 \mathrm{~s}$ period cyclic loadings, and result in a much lower inclined capacity. As the number of cycle increases, the failure mode of the model caisson becomes similar (vertical pullout) for different cyclic periods, and the increase velocity and the peak of the inclined resistance would also coincide well.

In conclusion, except for the loading angle, the previous cyclic loadings are also critical in determining the failure mode of a suction caisson in a soft clay seabed. After a series of cyclic loadings, the suction 
caisson becomes more inclined to produce vertical pullout motion at failure rather than a combined mode of vertical motion, horizontal motion and anticlockwise rotation. According to API RP 2SK [8], for the cases in which the vertical pullout is dominant, the FOS for a permanent, intact mooring is 2.0 (regardless of loading angle at the pad-eye), which is much larger than those for the horizontal (1.6) or the combined failure modes $(1.6<F O S<2.0)$. Therefore, the effects of the loading condition and the loading history on the failure mode should be considered in the design of the capacity of a suction caisson.

\section{Acknowledgments}

The authors would like to acknowledge the support of International Science \& Technology Cooperation Program of China (2015DFE72830), the Grant No. 51325901 and 51209183 from the National Natural Science Foundation of China, the Project No. LY15E090002 supported by Zhejiang Provincial Natural Science Foundation of China, and the Fundamental Research Funds for the Central Universities.

\section{References}

[1] Randolph, M. F., Cassidy, M., Gourvenec, S., Erbrich, C., 2005. Challenges of Offshore Geotechnical Engineering. In: Proceedings of the International Conference on Soil Mechanics and Geotechnical Engineering, Plenary session D. pp. 1-54.

[2] Randolph. M. F., Gaudin, C., Gourvenec, S. M., White, D. J., Boylan, N., Cassidy, M. J., 2011. Recent advances in offshore geotechnics for deep water oil and gas developments. Ocean Engineering 38, 818-834.

[3] EI-Sherbiny, R. M., 2005. Performance of suction anchor anchors in normally consolidated Clay. Ph.D. Dissertation. The University of Texas at Austin.

[4] Andersen, K. H., Murff, J. D., Randolph, M. F., Clukey, E. C., Erbrich, C. T., Jostad, H. P., Hansen, B., Aubeny, C., Sharma, P., Supachawarote, C., 2005. Suction anchors for deepwater applications. In: Proceedings of International Symposium on Frontiers in Offshore Geotechnics. pp. 3-30.

[5] Randolph, M. F., House A. R., 2002. Analysis of suction caisson capacity in clay. In: Proceedings of the 34th Offshore Technology Conference. Houston, OTC14236. pp. 1-11.

[6] Wang, L. Z., Guo, Z., Yuan, F., 2010. Quasi-static three-dimensional analysis of suction anchor mooring system. Ocean Engineering 37(13), 1127-1138.

[7] Andersen, K. H., Jostad, H. P., 1999. Foundation design of skirted foundations and anchors in clay. In: 
Proceedings of the 31st Offshore Technology Conference. Houston, OTC 10824. pp. 383-392.

[8] API RP 2SK, 2005. Recommended Practice for Design and Analysis of Stationkeeping Systems for Floating Structures, third edition. Washington D.C.

[9] Andersen, K. H., Dyvik, R., SchrØder, K., Hansteen, O. E., Bysveen, S., 1993. Field tests of anchors in clay II: Predictions and interpretation. Journal of Geotechnical Engineering 119(10), 1532-1549.

[10] El-Gharbawy, S. L., Olson, R. E., 1999. The cyclic pullout capacity of suction caisson foundations. In: Proceedings of 9th International Offshore and Polar Engineering Conference. pp. 660-667.

[11] Luke, A. M., 2002. Axial capacity of suction caissons in normally consolidated kaolin. Ph.D. Dissertation. University of Texas at Austin.

[12] Clukey, E. C., Templeton, J. S., Randolph, M. F., Phillips, R., 2004. Suction caisson response under sustained loop current loads. In: Proceedings of 36th Offshore Technology Conference. Houston, OTC16843. pp. 1-9.

[13] Chen, W., Randolph, M. F., 2007. Uplift capacity of suction caissons under sustained and cyclic loading in soft clay. Journal of Geotechnical and Geoenvironmental Engineering 133(11), 1352-1363. [14] Guo, Z., Wang, L. Z., Yuan, F., Li, L. L., 2012. Model tests on installation techniques of suction caissons in a soft clay seabed. Applied Ocean Research 34, 116-125.

[15] Deng, W., Carter, J. P., 2000. A theoretical study of the vertical uplift capacity of suction caisson. In: Proceedings of the 10th International Offshore and Polar Engineering Conference. Seattle. Vol. 11, pp. 342-349.

[16] Thorel, L., Garnier, J., Rault, G., Bisson, A., 2005. Vertical uplift capacity of suction caisson in clay. In: Proceedings of International Symposium on Frontiers in Offshore Geotechnics. pp. 273-279. 


\section{Figures}

Fig. 1 Variation of optimal depth with the loading angle [3]

Fig. 2 Different components of forces acting on the suction caisson [6]

Fig. 3 Locations of PPTs along the caisson wall

Fig. 4 (a) water content; (b) total unit weight of soil; (c) over consolidation ratio

Fig. 5 (a) undrained shear strength; (b) soil sensitivity

Fig. 6 Jacking installation of the model caisson: (a) dead-weight loading rig; (b) typical soil resistance profile during jacking

Fig. 7 Inclined loading of the model caisson

Fig. 8 Test procedure for one-way cyclic loadings

Fig. 9 The two-dimensional motion-measurement system

Fig. 10 Motions of the model caisson for different loading angles

Fig. 11 Pore-pressures at different locations of model caisson: (a) LP-1; (b) LP-2; (c) LP-3

Fig. 12 Short-term static capacities for different loading angles: (a) inclined resistance to the model caisson; (b) load components at the pad-eye

Fig. 13 Previous cyclic loadings with different cyclic amplitudes: (a) NP-1; (b) NP-2; (c) NP-3

Fig. 14 Position changes of the pad-eye after cyclic loadings in tests NP-1, NP-2 and NP-3

Fig. 15 Test results for different cyclic amplitudes: (a) motions of the model caisson; (b) inclined resistance versus pad-eye displacement

Fig. 16 Previous cyclic loadings with different cycle numbers: (a) NP-3; (b) NP-4; (c) NP-5

Fig. 17 Position changes of the pad-eye after cyclic loadings in tests NP-3, NP-4 and NP-5

Fig. 18 Test results for different cycle numbers: (a) motions of the model caisson; (b) inclined resistance versus pad-eye displacement

Fig. 19 Previous cyclic loadings with different cyclic periods: (a) NP-6; (b) NP-7; (c) NP-8; (d) NP-9

Fig. 20 Position changes of the pad-eye after cyclic loadings in tests NP-6, NP-7, NP-8 and NP-9

Fig. 21 Test results after 50 cyclic loadings: (a) motions of model caisson; (b) inclined resistance versus pad-eye displacement

Fig. 22 Test results after 100 cyclic loadings: (a) motions of model caisson; (b) inclined resistance versus pad-eye displacement 


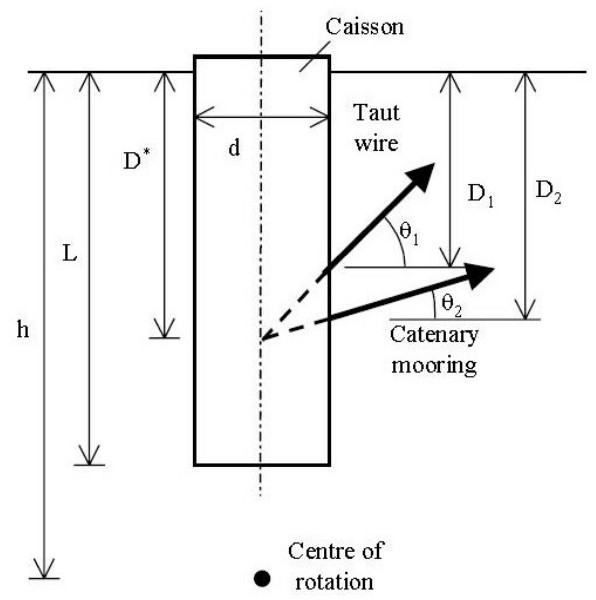

Fig. 1 Variation of optimal depth with the loading angle [3] 


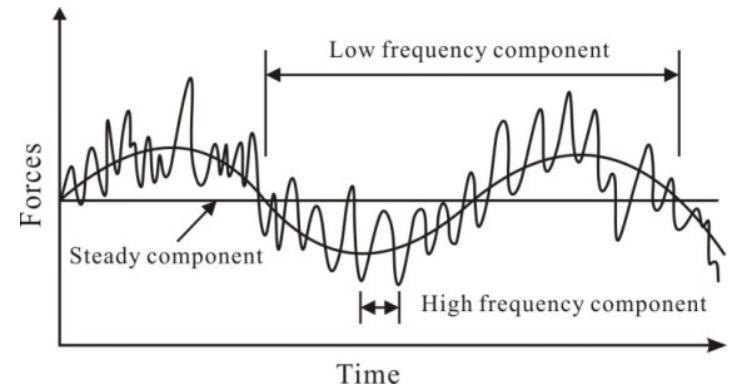

Fig. 2 Different components of forces acting on the suction caisson [6] 


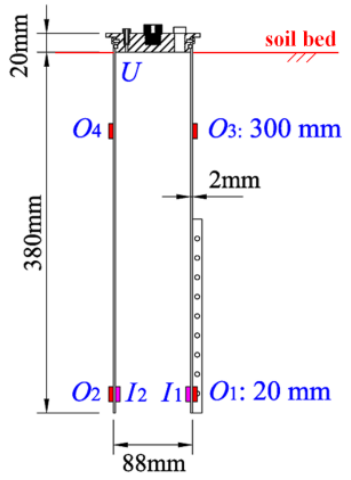

Fig. 3 Locations of PPTs along the caisson wall 


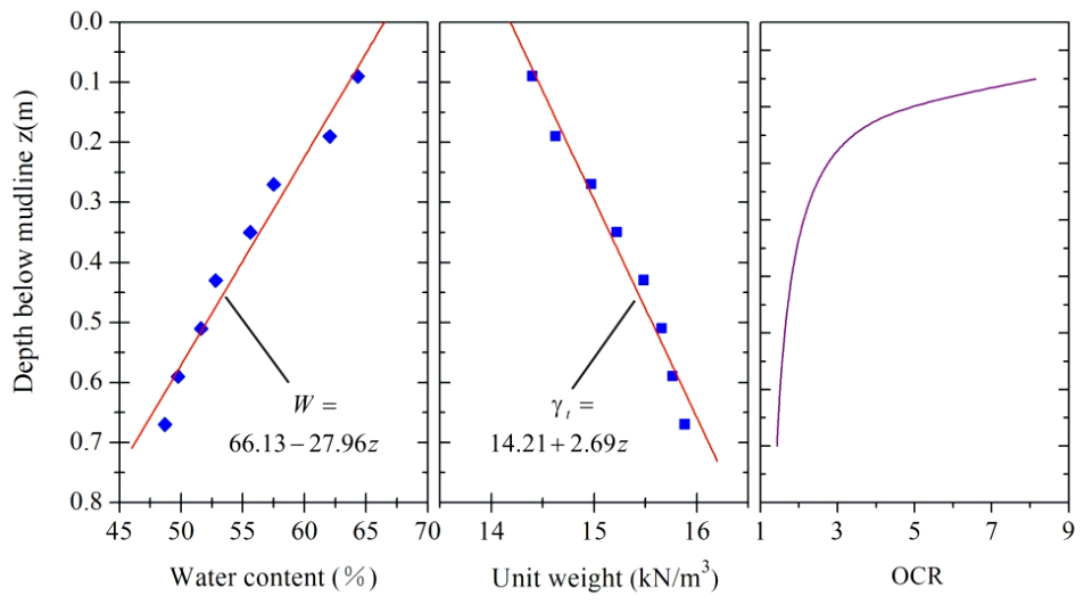

Fig. 4 (a) water content; (b) total unit weight of soil; (c) over consolidation ratio 


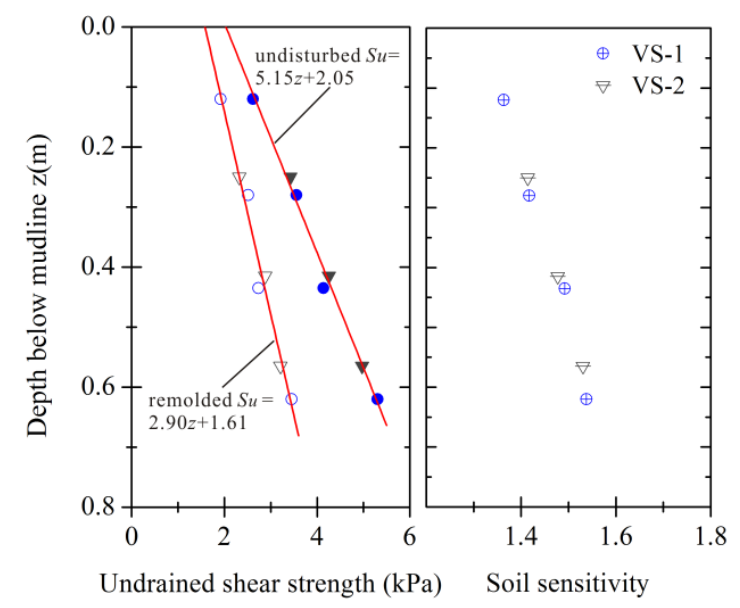

Fig. 5 (a) undrained shear strength; (b) soil sensitivity 


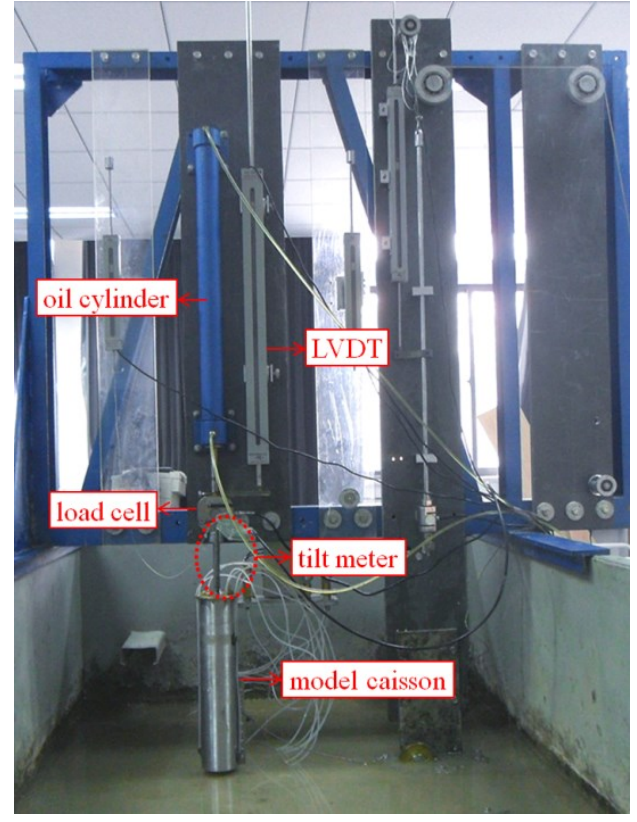

(a) dead-weight loading rig

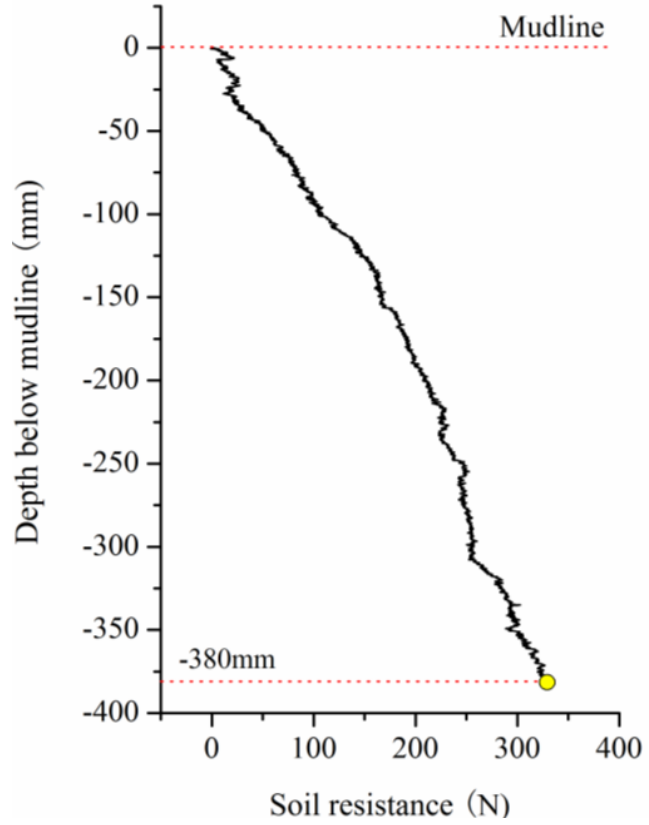

(b) typical soil resistance profile during jacking

Fig. 6 Jacking installation of the model caisson 


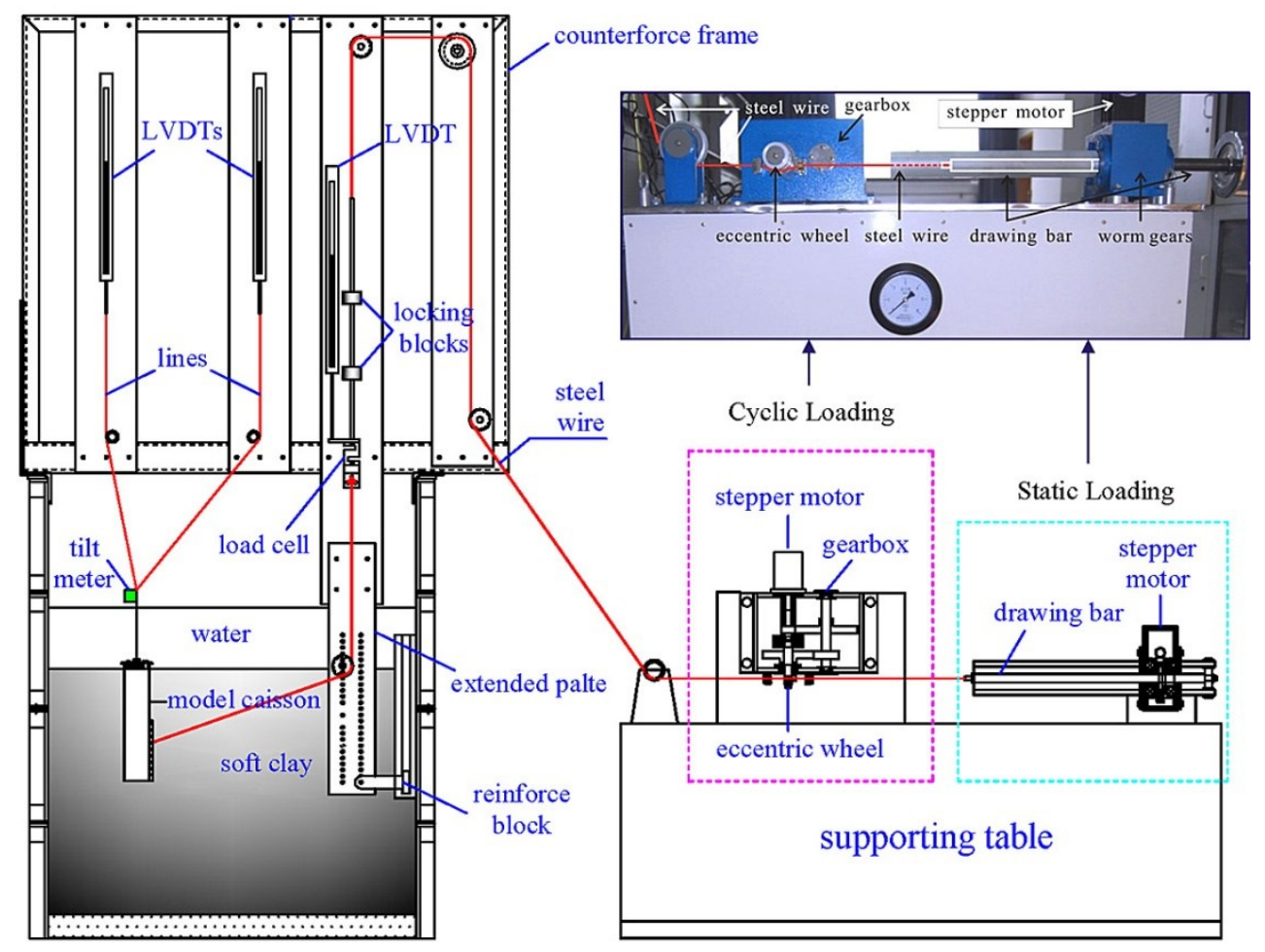

Fig. 7 Inclined loading of the model caisson 


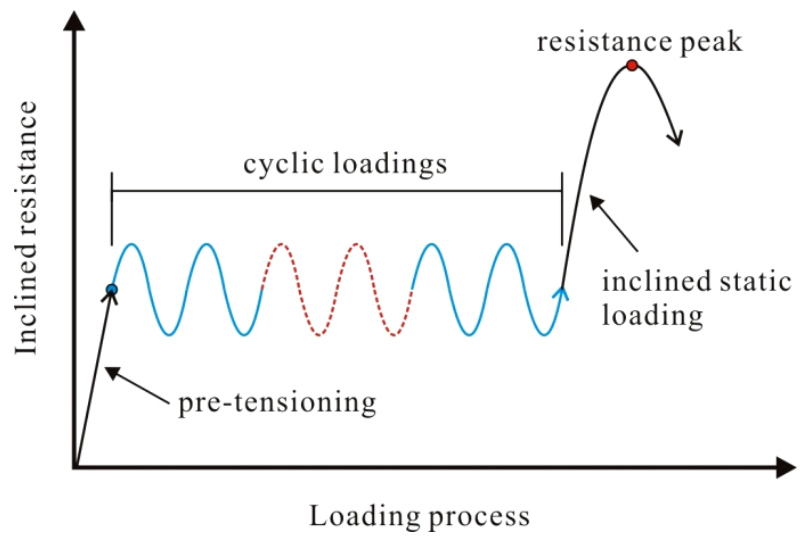

Fig. 8 Test procedure for one-way cyclic loadings 


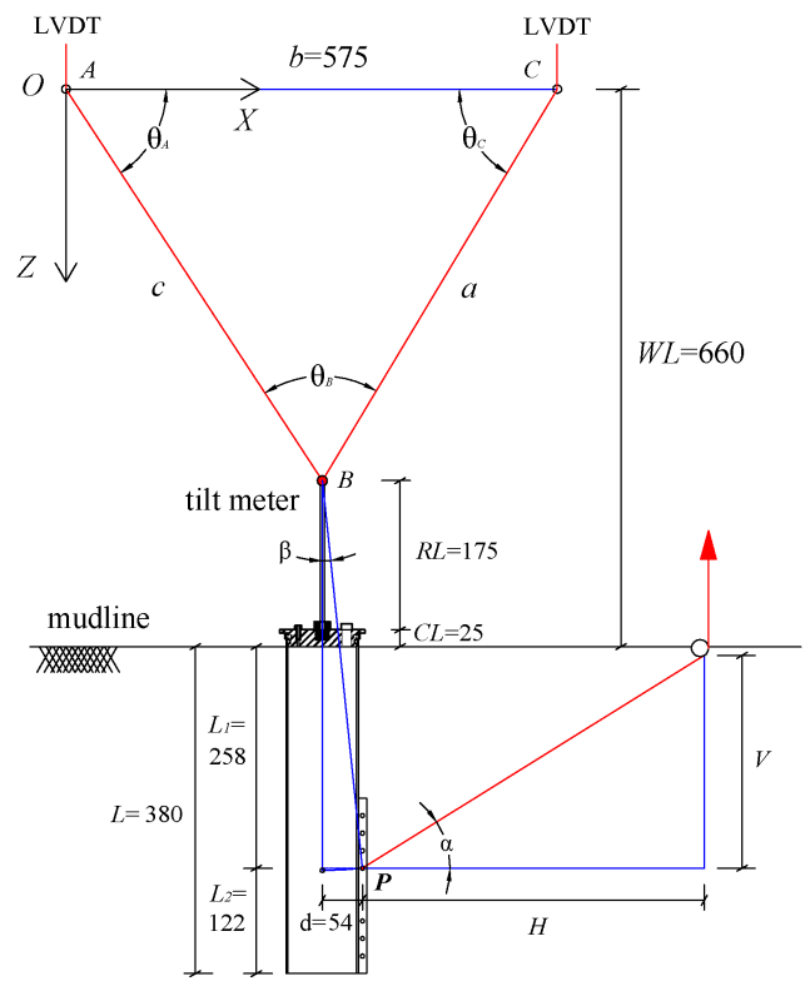

Fig. 9 The two-dimensional motion-measurement system 


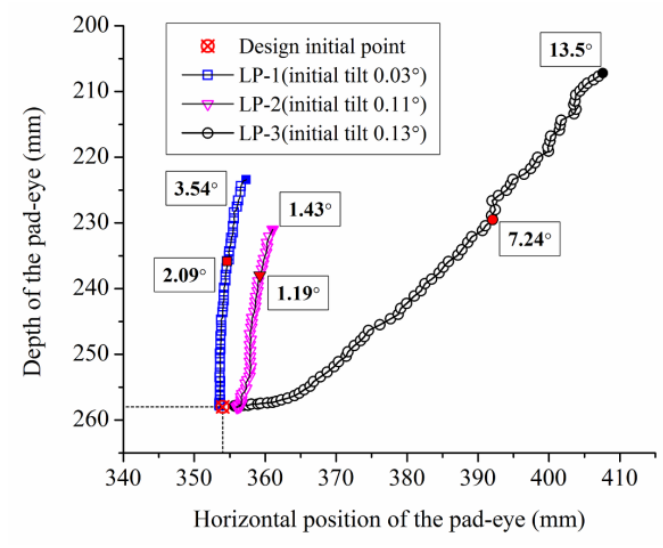

Fig. 10 Motions of the model caisson for different loading angles 


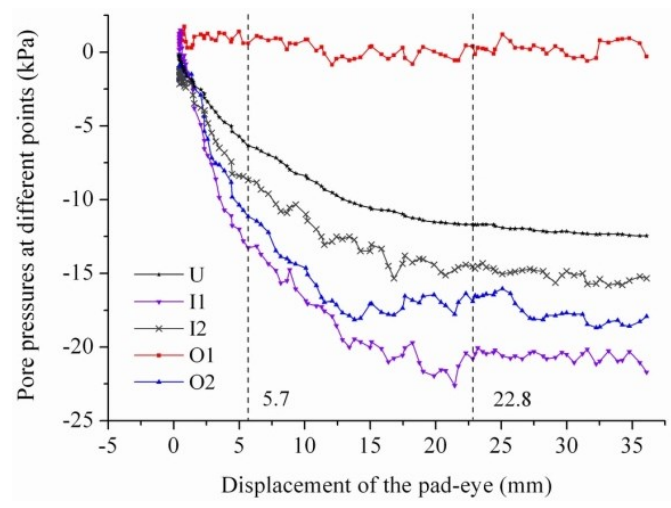

(a) LP-1

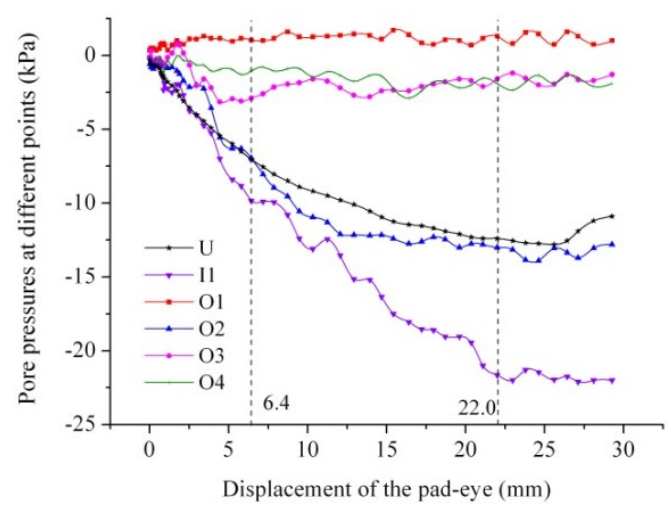

(b) LP-2

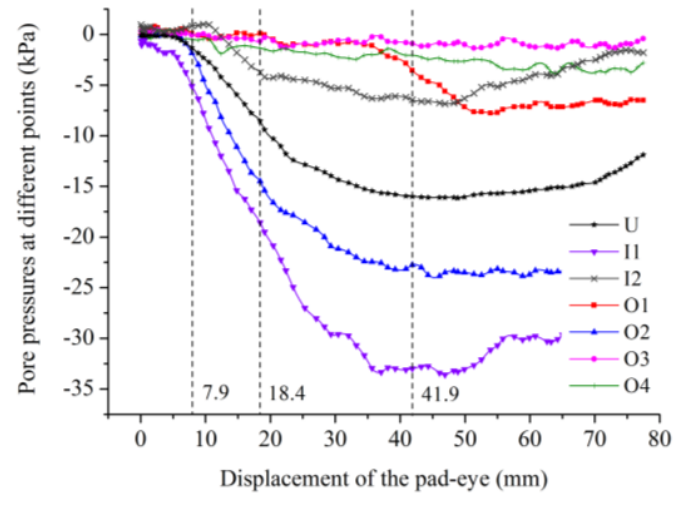

(c) LP-3

Fig. 11 Pore-pressures at different locations of model caisson 


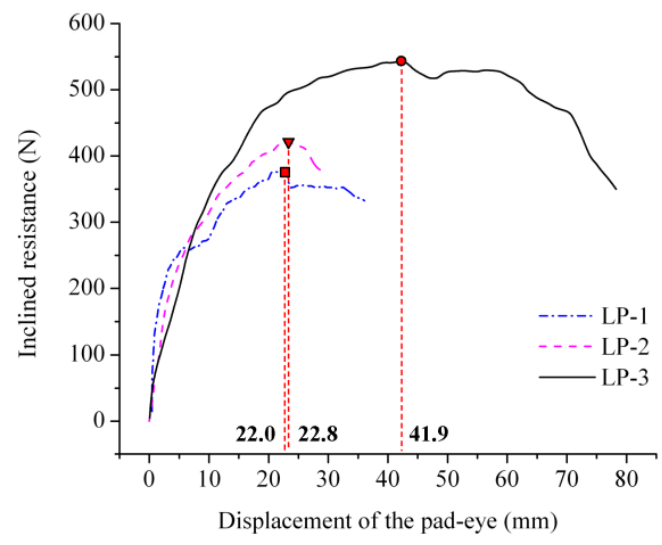

(a) inclined resistance to the model caisson

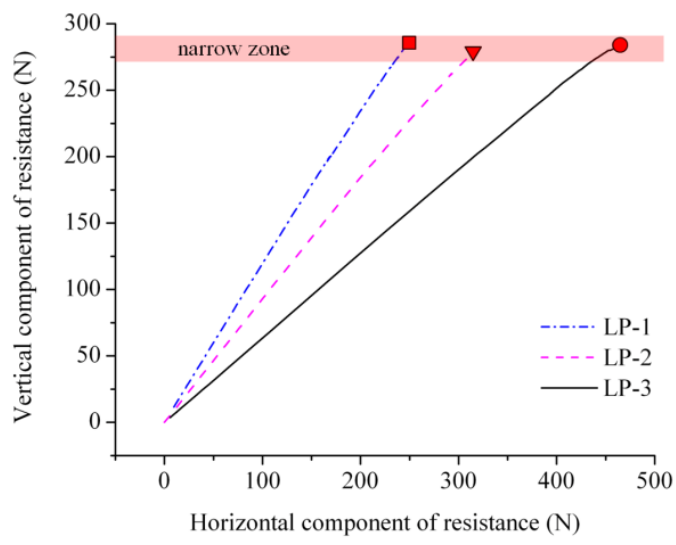

(b) load components at the pad-eye

Fig. 12 Short-term static capacities for different loading angles 


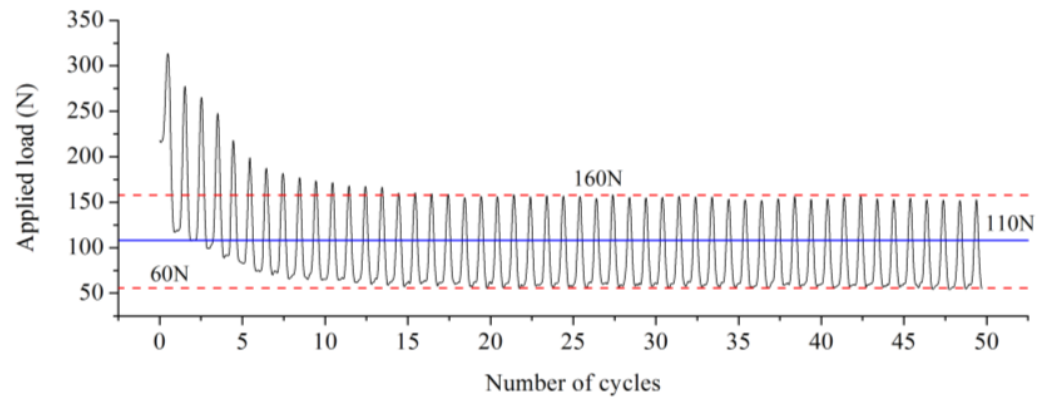

(a) NP-1

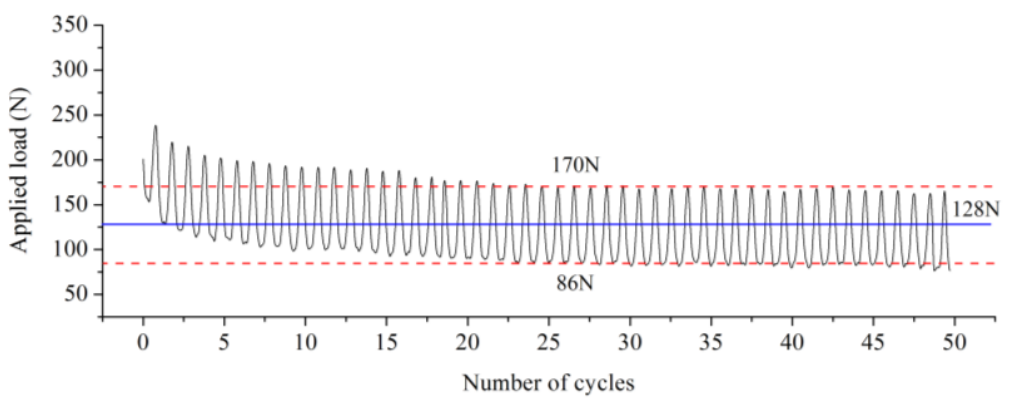

(b) NP-2

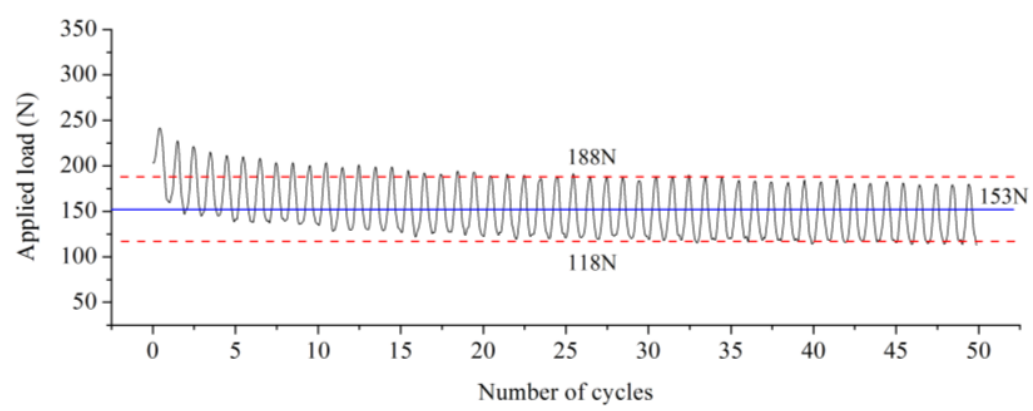

(c) NP-3

Fig. 13 Previous cyclic loadings with different cyclic amplitudes 


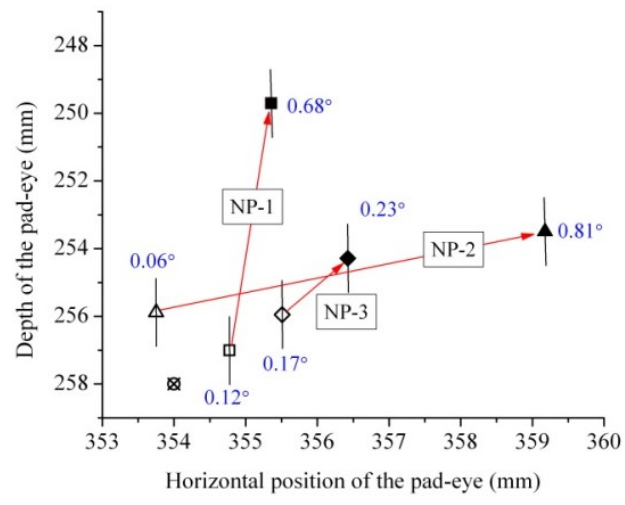

Fig. 14 Position changes of the pad-eye after cyclic loadings in tests NP-1, NP-2 and NP-3 


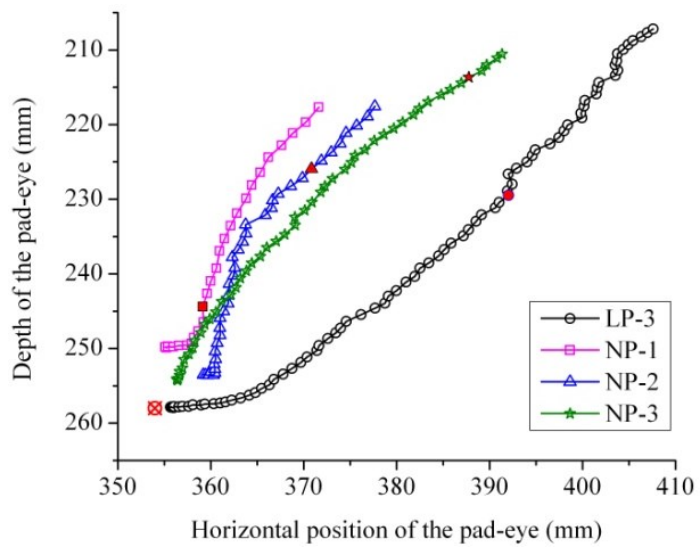

(a) motions of the model caisson

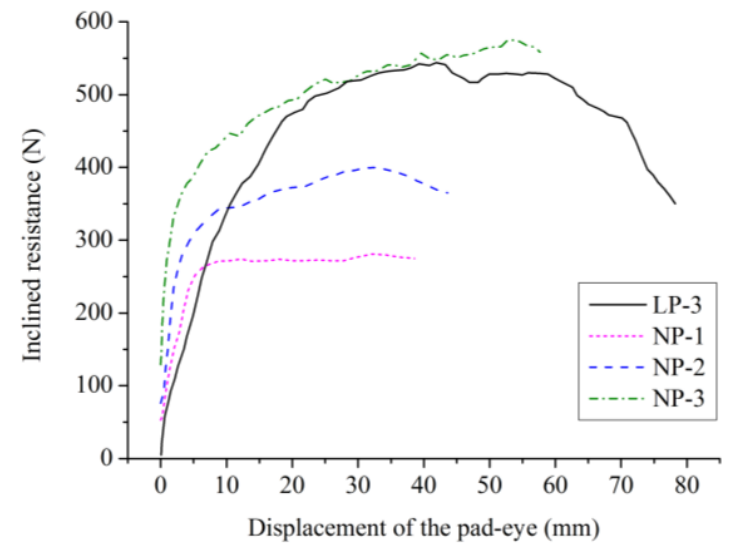

(b) inclined resistance versus pad-eye displacement

Fig. 15 Test results for different cyclic amplitudes 


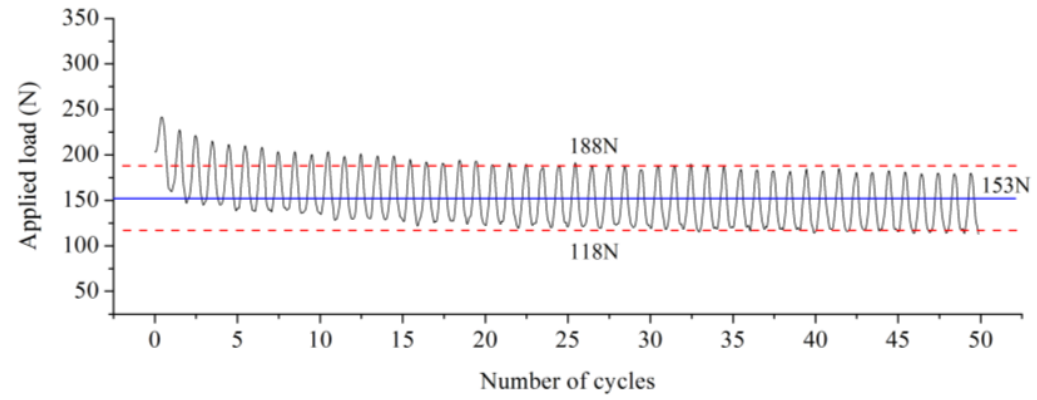

(a) NP-3

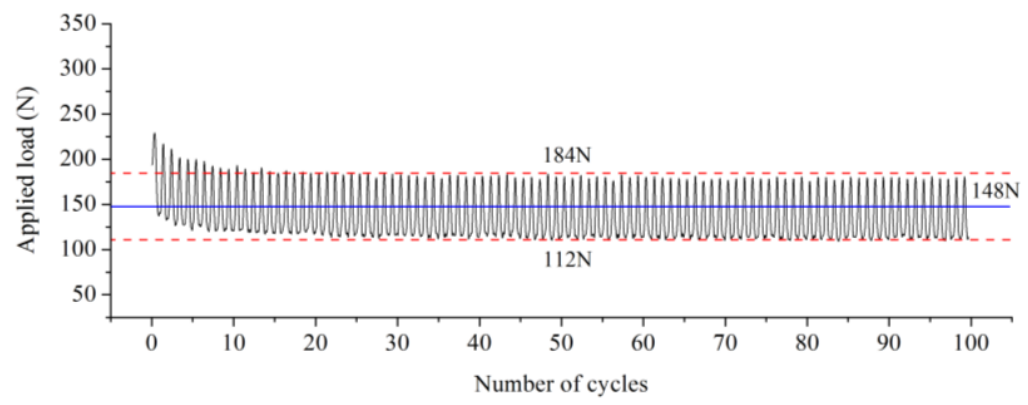

(b) NP-4

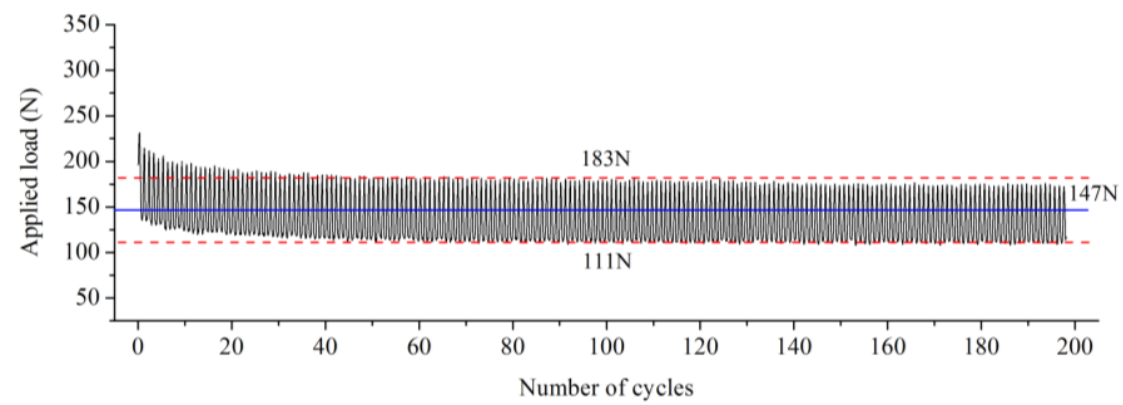

(c) NP-5

Fig. 16 Previous cyclic loadings with different cycle numbers 


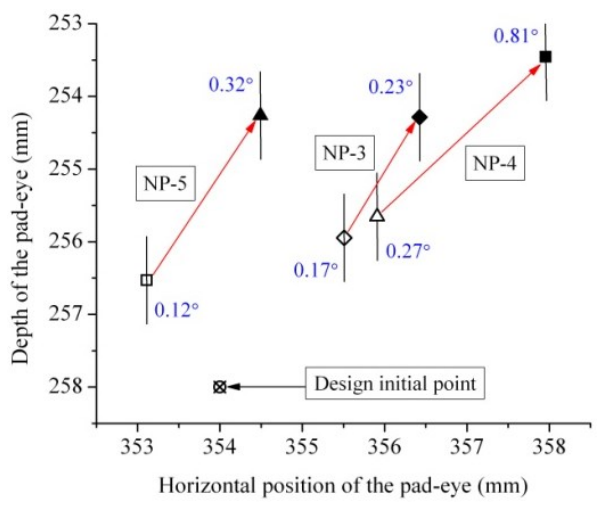

Fig. 17 Position changes of the pad-eye after cyclic loadings in tests NP-3, NP-4 and NP-5 


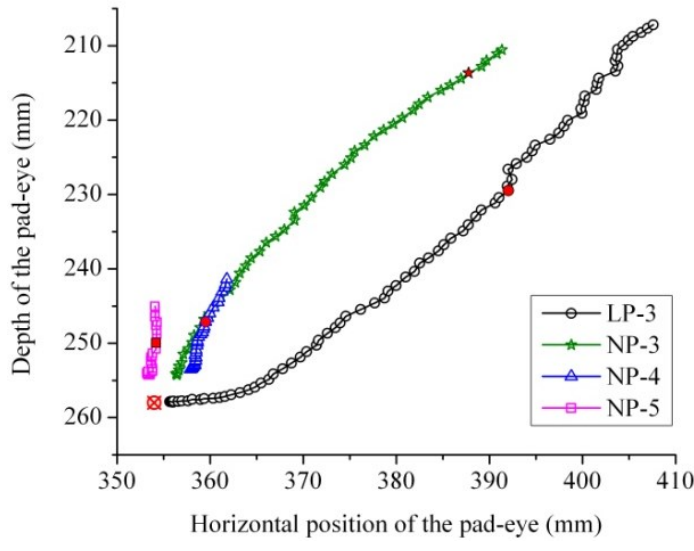

(a) motions of the model caisson

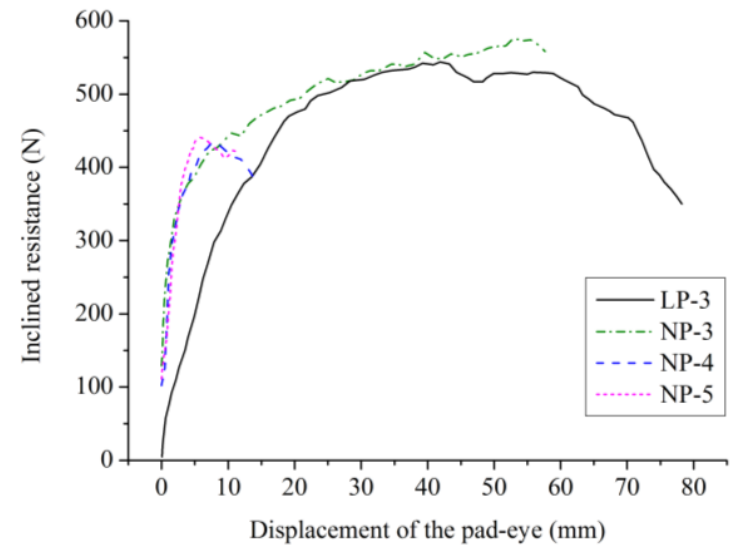

(b) inclined resistance versus pad-eye displacement

Fig. 18 Test results for different cycle numbers 


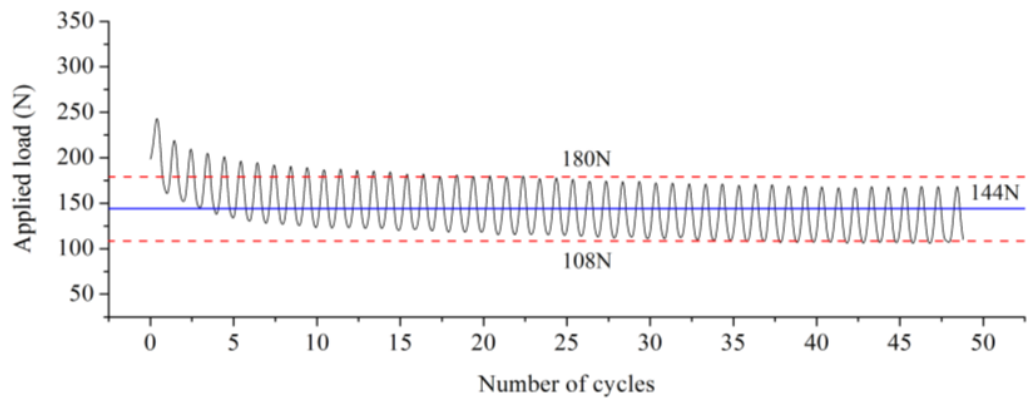

(a) NP-6

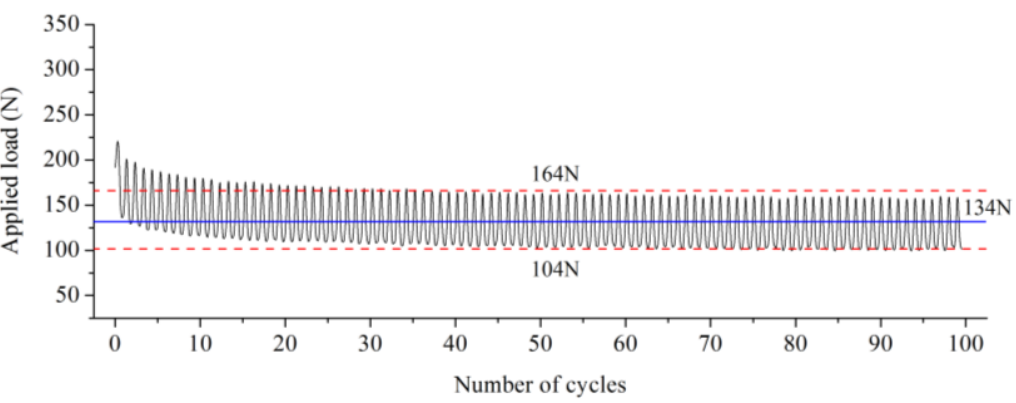

(b) NP-7

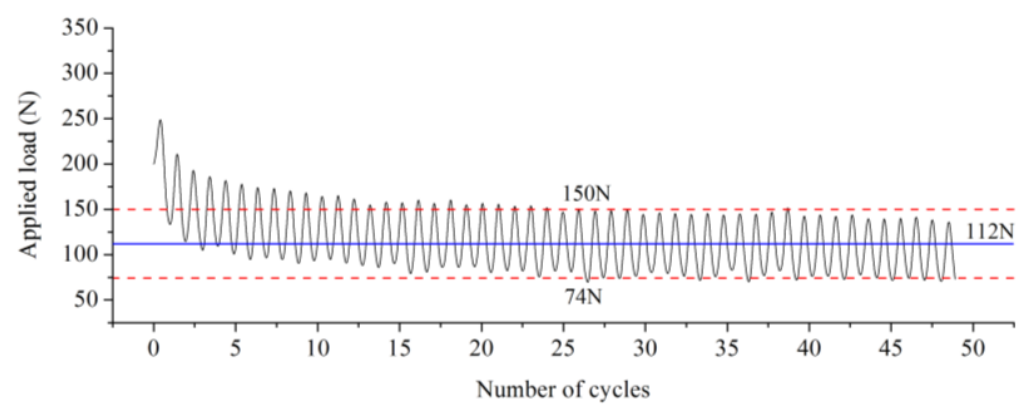

(c) NP-8

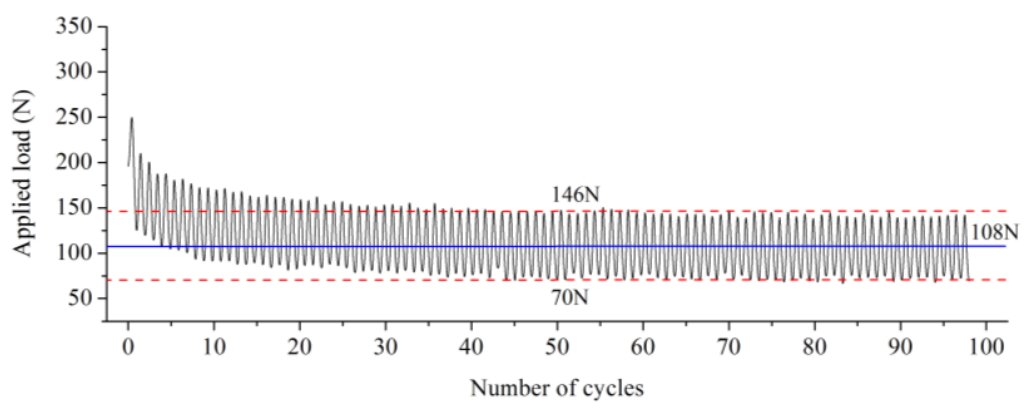

(d) NP-9

Fig. 19 Previous cyclic loadings with different cyclic periods 


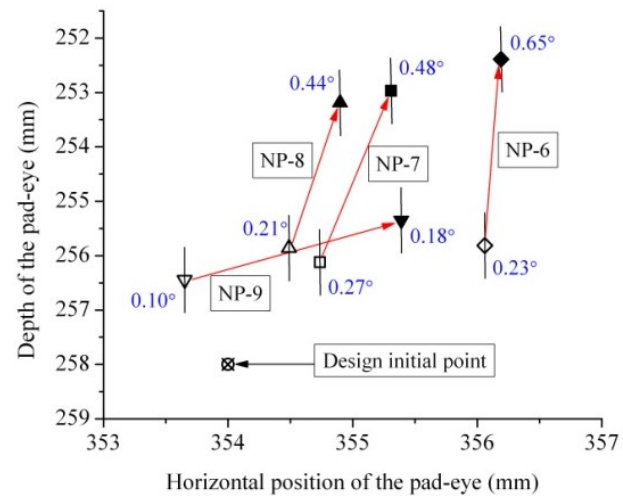

Fig. 20 Position changes of the pad-eye after cyclic loadings in tests NP-6, NP-7, NP-8 and NP-9 


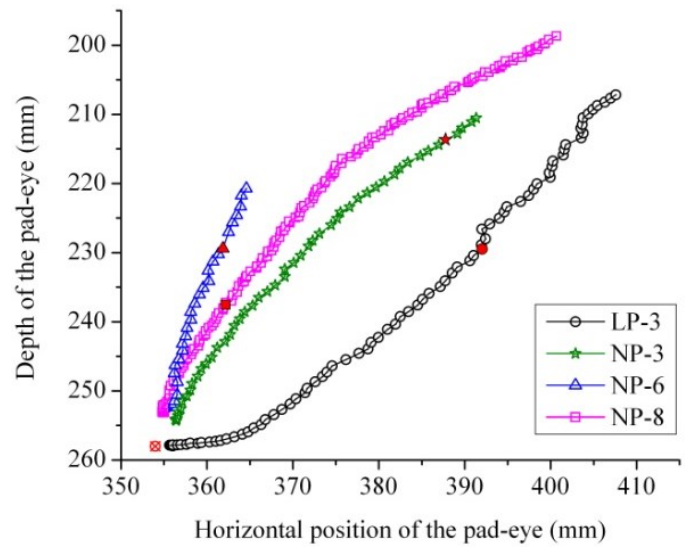

(a) motions of model caisson

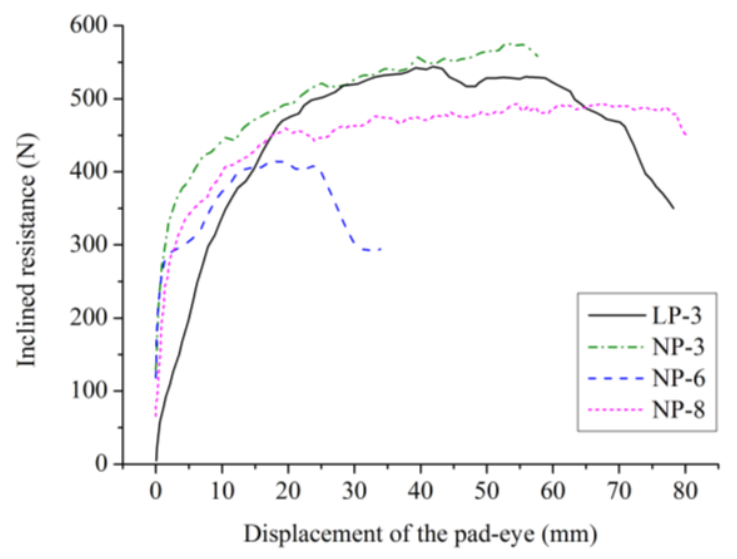

(b) inclined resistance versus pad-eye displacement

Fig. 21 Test results after 50 cyclic loadings 


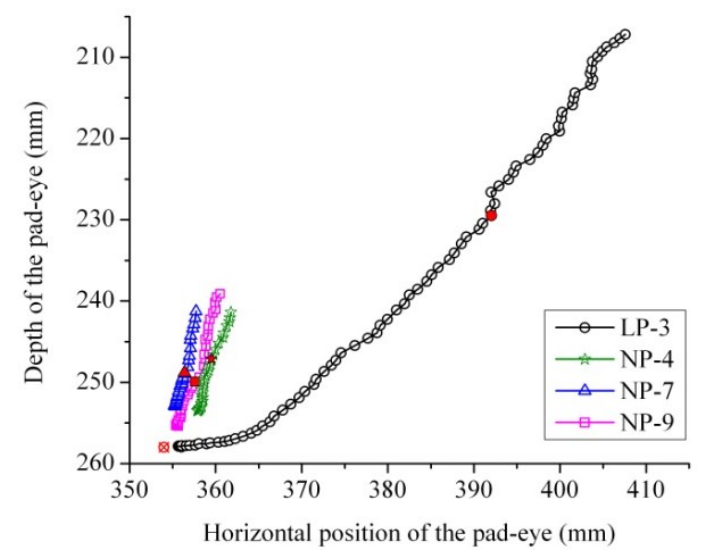

(a) motions of model caisson

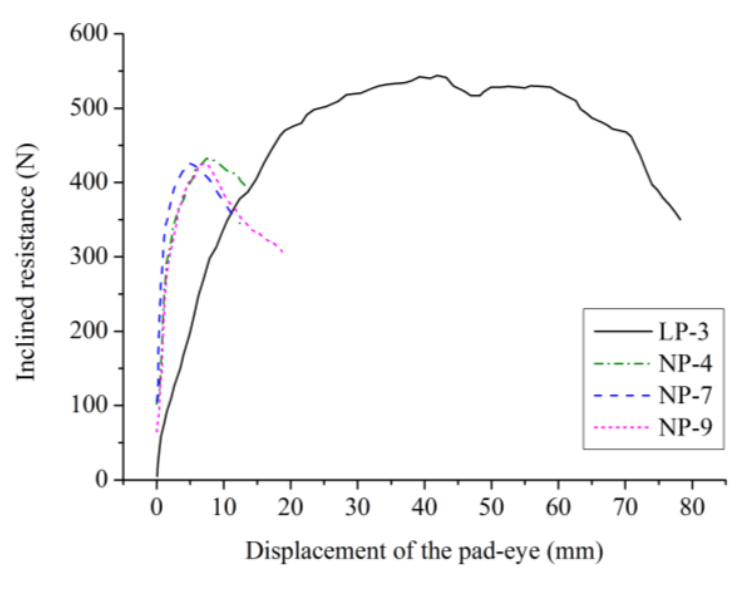

(b) inclined resistance versus pad-eye displacement

Fig. 22 Test results after 100 cyclic loadings 


\section{Tables}

Table 1 Summary of the model tests 
Table 1 Summary of the model tests

\begin{tabular}{|c|c|c|c|c|c|c|}
\hline test ID & load type & \multicolumn{3}{|c|}{ elevation angle $\left(^{\circ}\right)$} & \multicolumn{2}{|c|}{ load speed $(\mathrm{mm} / \mathrm{s})$} \\
\hline LP-1 & \multirow{4}{*}{$\begin{array}{l}\text { inclined } \\
\text { static } \\
\text { loading }\end{array}$} & \multicolumn{3}{|c|}{50.2} & \multicolumn{2}{|c|}{1.0} \\
\hline LP-2 & & \multicolumn{3}{|c|}{42.8} & \multicolumn{2}{|c|}{1.0} \\
\hline LP-3 & & \multicolumn{3}{|c|}{32.0} & \multicolumn{2}{|c|}{1.0} \\
\hline & & period $(\mathrm{s})$ & amplitude & number & elevation angle $\left({ }^{\circ}\right)$ & load speed $(\mathrm{mm} / \mathrm{s})$ \\
\hline NP-1 & & 100 & level 1 & 50 & 32.0 & 1.0 \\
\hline NP-2 & & 100 & level 2 & 50 & 32.0 & 1.0 \\
\hline NP-3 & inclined & 100 & level 3 & 50 & 32.0 & 1.0 \\
\hline NP-4 & $\begin{array}{l}\text { static } \\
\text { loading }\end{array}$ & 100 & level 3 & 100 & 32.0 & 1.0 \\
\hline NP-5 & after & 100 & level 3 & 200 & 32.0 & 1.0 \\
\hline NP-6 & $\begin{array}{l}\text { one-way } \\
\text { cyclic }\end{array}$ & 50 & level 3 & 50 & 32.0 & 1.0 \\
\hline NP-7 & loadings & 50 & level 3 & 100 & 32.0 & 1.0 \\
\hline NP-8 & & 10 & level 3 & 50 & 32.0 & 1.0 \\
\hline NP-9 & & 10 & level 3 & 100 & 32.0 & 1.0 \\
\hline
\end{tabular}

